\section{Occurrence of potential plastic microfibers in mussels and anchovies sold for human consumption: Preliminary results}

\author{
Serena Santonicola, ${ }^{1}$ Michela Volgare, ${ }^{2}$ \\ Emilia Di Pace, ${ }^{2}$ Mariacristina Cocca, ${ }^{2}$ \\ Raffaelina Mercogliano, ${ }^{3}$ \\ Giampaolo Colavita ${ }^{1}$ \\ ${ }^{1}$ Department of Medicine and Health \\ Sciences "V. Tiberio", University of \\ Molise, Campobasso; ${ }^{2}$ Institute of \\ Polymer, Composites and Biomaterials, \\ National Research Council of Italy, \\ Pozzuoli (NA); ${ }^{3}$ Department of \\ Veterinary Medicine and Animal \\ Production, University of Naples, Italy
}

\begin{abstract}
There is a global concern over the impact of microplastics on marine species and trophic webs. Microfibers commonly represent the greater portion of microplastics in the aquatic environment, but little is known about fiber uptake and accumulation by marine biota. The aim of the study was to investigate the potential plastic microfiber contamination in mussels (Mytilus galloprovincialis) and anchovies (Engraulis encrasicolus) from the Tyrrhenian Sea sold for human consumption. Anthropogenic debris was extracted from the digestive tracts of fish and the whole shellfish using a $10 \% \mathrm{KOH}$ solution and quantified under a light microscope. The preliminary results showed the occurrence of potential plastic and natural microfibers in $73 \%$ of the samples. On average mussels contained 1.33 microfibers/g w.w. and 7.66 items/individual, while anchovies contained 9.06 microfibers/individual. Considering that mussels are consumed as a whole, and small pelagic fish, as anchovy, may be eaten without removing the gastrointestinal tract, microfiber contamination may lead to human exposure. More research is required to adequately assess the risk that microplastics, including microfibers, may pose for food safety and human health.
\end{abstract}

\section{Introduction}

The occurrence of microplastics, defined as plastic particles smaller than 5 $\mathrm{mm}$, is recognized as an emerging threat to aquatic ecosystems (GESAMP, 2015).
These particles are categorized by source, as primary or secondary microplastics, and based on color and shape (fragments, foams, films, and fibers) (EFSA, 2016). Plastic microfibers, a common form of microplastic pollution, are the most numerous debris reported in marine environments (Doucet et al., 2021). The definition of microfibers as a specific class among all microplastic pollutants has been recently proposed (Avio et al., 2020).

Fibers, released both from washing machines and from the wastewater treatment plant, can enter the marine environment and persist for decades (Halstead et al., 2018; Avio et al., 2020). Microfiber contamination could be also a result of the fragmentation of fishing nets (Savoca et al., 2019).

Due to the high concentrations of microfibers along the urbanized coasts, there is a need to quantify and assess the extent of fiber ingestion by marine biota, and the ecological significance of the phenomenon (Halstead et al., 2018; Capone et al., 2020). Microfibers have been detected in the gastrointestinal (GI) tracts and tissues of several marine vertebrates and invertebrates, including commercially important species, accounting for over $90 \%$ of the debris observed in fish from the Mediterranean Sea (Rochman et al., 2015; Halstead et al., 2018; Rios-Fuster et al., 2019; Capone et al., 2020). Ingested microfibers can cause digestive obstruction and carry chemical pollutants that may harm biota (Catarino et al., 2018; Doucet et al., 2021). However, far less is known about plastic and natural microfibers, despite the evidence they pose a risk to the environment (Doucet et al., 2021).

In order to better understand the impact of microfiber contamination, the selection of species included organisms from different habitats and feeding strategies may reflect the environmental condition in the different marine compartments (Avio et al., 2020). Mussels (Mytilus spp.) and anchovies (Engraulis spp) are among proposed indicators for microplastic pollution in the Mediterranean waters, due to their wide spatial distribution, commercial importance, habitat and feeding strategies, as well as documented microplastic ingestion (Collard et al., 2017; Fossi et al., 2018; Li et al., 2019).

Mussels (Mytilus galloprovincialis), as benthic extensive filter-feeding organisms, may accumulate microplastics (Renzi et al., 2018; Mercogliano et al., 2021). Correlations between the types and abundance of microplastics in the environment and those found in the soft tissues of mussels were found (Ward et al., 2019). Short
Correspondence: Serena Santonicola, Department of Medicine and Health Sciences "V. Tiberio, University of Molise, Via F. De Santis, 86100 Campobasso, Italy.

E-mail: serena.santonicola@unimol.it

Key words: Microplastics, Microfibers, Mussels, Anchovies, Human exposure

Contributions: The authors contributed equally.

Conflict of interest: The authors declare no potential conflict of interest.

Funding: This study was supported by the research project "SIstemi di Rilevamento dell'Inquinamento Marino da Plastiche e successivo recupero-riciclo. SIRIMAP PON project" from the Ministry of Education, Italy.

Received for publication: 9 July 2021 Revision received: 5 November 2021.

Accepted for publication: 8 November 2021

This work is licensed under a Creative Commons Attribution-NonCommercial 4.0 International License (CC BY-NC 4.0).

(C) Copyright: the Author(s), 2021

Licensee PAGEPress, Italy

Italian Journal of Food Safety 2021; 10:9962

doi:10.4081/ijfs.2021.9962

fibers may be retained for a long period in the mussel gut, but the accumulation and retention of microfibers were also observed in all organs of mussels including foot and mantle (Catarino et al., 2018; Kolandhasamy et al., 2018; Ward et al., 2019).

Engraulis encrasicolus (European anchovy, Linnaeus, 1758) is the most important species landed among all pelagic fish in the Mediterranean Sea, accounting for approximately $50 \%$ of the total (FAO, 2011; Patti et al., 2018). Anchovies have a particular feeding strategy that combines both filter and particulate feeding activities and may ingest microfibers both through filtration and mistaking them with zooplankton (Capone et al., 2020). This species, like mussels, is a key candidate also to assess microplastic exposure to the consumers (Smith et al., 2018). In fact, although demersal fish are usually eviscerated before consumption, both fresh and dried small fishes, like anchovies, are often consumed as a whole (Compa et al., 2018; Renzi et al., 2019).

The aim of this study was to assess the occurrence of potential plastic microfibers in mussels ( $M$. galloprovincialis) and anchovies ( $E$. engrasicolus) from the 
Tyrrhenian Sea sold for human consumption and to provide a perspective about the implications for food safety and consumer health.

\section{Materials and methods}

\section{Materials}

Sodium Chloride, Hydrogen Peroxide solution $30 \%$ and Potassium hydroxide were purchased from Carlo Erba (Val De Reuil, France). Cellulose nitrate (pore size 8 $\mu \mathrm{m})$ and acetate (pore size $0.45 \mu \mathrm{m}$ ) filters were provided by Sartorius Stedim Biotech (Gottingen, Germany).

The filtrating system was provided by Advantec (Dublin, CA 94568, USA).

\section{Sample collection}

A number of n.15 samples of M. galloprovincialis and n.15 E. encrasicolus from the Tyrrhenian Sea (FAO subarea 37.1, division 37.1.3) were purchased from fish markets located in Campania Region, Italy. At the time of sampling, fresh mussels were sold loose, while fresh anchovies were exposed on counter steel. The samples were then stored at $-20^{\circ} \mathrm{C}$ prior to dissection. At the time of analyses, mussels length was recorded with calibre, and the shells were carefully washed with distilled water, previously filtered on $0.45 \mu \mathrm{m}$ cellulose acetate membrane, to remove associated debris. A small knife was inserted between the two valves on the dorsal side and the anterior adductor muscle was cut to open the valves, which were removed, before the weight recording. Anchovies were put on aluminium foil, and the total length and weight of each fish were recorded with calibre and a digital balance, respectively. The GI tracts were removed from the esophagus to the anal sphincter and then weighed.

\section{Contamination assessment}

As contamination precaution, personnel used protective laundered cotton lab coats and vinyl gloves when handling samples, and particular attention was paid to limit the wearing of synthetic clothes. Extraction procedures were carried out in a clean room, limiting access to staff. All of the liquids (freshwater, saltwater, and hydrogen peroxide solution) were filtered, before use, with $0.45 \mu \mathrm{m}$ cellulose acetate filters. Samples were always covered with aluminum foil and exposed only during dissection. Glass apparatus were used instead of plastic. All glassware and other equipment were rinsed three times with filter water before use and between samples. Then all containers were covered with aluminium foils, which were kept during digestion, stirring, decantation, and filtration steps. After filtration, membranes were kept in glass Petri dishes, previously rinsed with prefiltered water. All nearby work surfaces were cleaned with filter water prior to use. For the correction of potential procedural contamination, one blank control without any tissue was carried out for every sample group (5-6 individuals) processed on the same day.

\section{Extraction method}

Animals were analyzed individually rather than in pools to improve data representativeness. The sample analysis was performed based on an extraction method previously validated (Mercogliano et al., 2021). Briefly, each sample was filled to $3 \mathrm{x}$ the volume of the tissues with a $10 \% \mathrm{KOH}$ solution and incubated overnight at $45^{\circ} \mathrm{C}$ in an oven to digest the organic material. After the digestion, a prefiltered saturated saline solution $\left(1.2 \mathrm{~g} / \mathrm{cm}^{3}\right)$ was used to separate the microplastics from the dissolved liquid of the soft tissue via floatation. Approximately $250 \mathrm{~mL}$ of saline solution was added to each sample and decanted for $10 \mathrm{~min}$. The overlying water was directly filtered over cellulose nitrate membrane filters (pore size of $8 \mu \mathrm{m}$ ) using a vacuum system. The filtration step was carried out twice in order to obtain a better extraction performance.

To allow the digestion of residual organic matter, then the filters were placed into clean Petri dishes in contact with a $15 \%$ $\mathrm{H}_{2} \mathrm{O}_{2}$ solution in an oven at $45^{\circ} \mathrm{C}$ overnight.

\section{Visual observation and identifica- tion of microfibers}

Following the chemical digestion, the filters were inspected using a light microscope (LEICA M205C) with a magnification of $0.78-16 x$. During this first phase, only the microfibers on the filter were identified, counted, and characterized. As the chemical characterization of particles was not performed, potential synthetic fibres were classified from natural according to some morphological characteristics. In particular, natural fibres (Figure 1) lack the three-dimensional bending that is typically observed in anthropogenic fibres (Figure 2) which should be equally thick, not tapered at the end, and not segmented nor do they appear as twisted flat ribbons (Savoca et al., 2019; Avio et al., 2020; Doucet et al., 2021). According to Doucet et al. (2021), prior to data analysis, microfibers counts within each blank, categorized by morphology, were subtracted from the counts of each associated sample. Microfibers that were probably derived from the cellulose filter degradation due to the action of hydrogen peroxide were not counted. The procedural blanks contained $3.5 \pm 2.12$ microfibers/filter.

\section{Evaluation of human exposure through mussel and anchovy consumption}

The consumer exposure to microfibers was calculated considering the consumption of a $225 \mathrm{~g}$ portion of mussels (EFSA, 2016), and the mean value of microfibers/g w.w. detected in the current study. For the evaluation of the exposure through the consumption of anchovies, the recommended weight of a fish portion (150 g), according to Crea (2017), and the mean value of microfibers/g w.w. of the whole individual were considered. Moreover, for a comprehensive evaluation of human exposure, in the worst-case scenario the highest number of microfibers/g w.w. detected in the analyzed samples and the recommended weight of a portion of mussels and anchovies were considered.

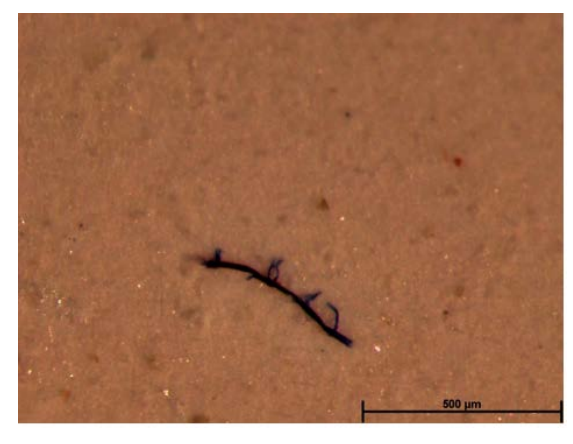

Figure 1. Representative microscope image of a potential natural fiber ingested by the investigated seafood.

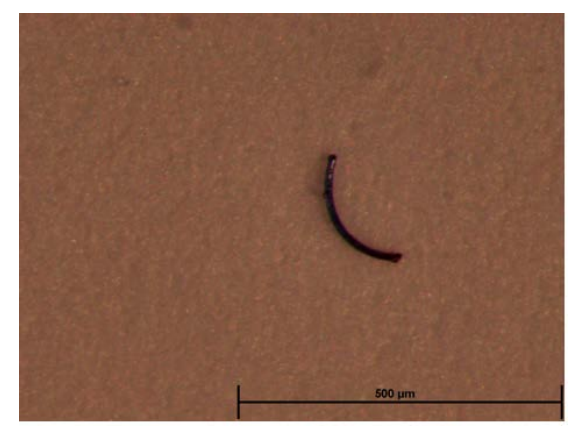

Figure 2. Representative microscope image of a potential synthetic fiber ingested by the investigated seafood. 


\section{Results}

\section{Biometric data}

The mean bivalves' length and weight were $6.63 \pm 0.99 \mathrm{~cm}$ and $6.93 \pm 3.06 \mathrm{~g}$, respectively. Anchovies showed a mean length of $10.96 \pm 0.74 \mathrm{~cm}$ and a weight of $12.39 \pm 2.42 \mathrm{~g}$. The anchovy GI tracts ranged from 0.37 to $1.27 \mathrm{~g}$.

\section{Microfibers in mussels}

Microfibers were found in $73.3 \%$ of commercial mussels coming from the Tyrrhenian Sea. The number of microfibers in mussels ranged from 0.00 to 4.52 microfibers/g w.w. with a mean value of 1.33 microfibers/g w.w. and 7.66 items/individual. The typical morphological features showed that the mean number of potential synthetic fibers was 0.61 items $/ g$ w.w., corresponding to 3.63 items/individual.

Smaller mussels (4-5.75g) contained more microfibers (1.69 items/g w.w.) than larger mussels (0.78 items/g w.w.). However, at this preliminary stage, due to the limited number of samples, it did not allow to highlight significant differences among mussel size groups.

The most common colors of fibers were blue $(46 \%)$, black $(27.32 \%)$, and transparent $(17.4 \%)$ (Figure 3$)$.

\section{Microfibers in anchovies}

Among the analyzed samples, $73 \%$ of commercial anchovies contained microfibers at levels ranging from 0.0 to 2.62 items/g w.w. considering the weight of the whole individual. On average, anchovy contained 9.06 microfibers/individual, of which 5.50 items/individual were identified as potential synthetic.

Black (35.46\%), blue (33.99\%), and transparent (13.05\%) fibers were the most abundant (Figure 4).

\section{Human exposure through mussel and anchovy consumption}

Bivalves, such as mussels, are consumed as a whole, and also small pelagic fish, as anchovy, may be eaten without removal of the digestive tract.

Considering a portion of $225 \mathrm{~g}$ of mussels (EFSA, 2016), the consumer may ingest 299.25 potential plastic and natural microfibers, while in the worst-case scenario, the exposure reaches 1,012 microfibers/portion of mussels. Regarding anchovies, a portion of $150 \mathrm{~g}$ (Crea, 2017) of individuals consumed as a whole may contain 135.6 potential synthetic and natural microfibers, and in the worst-case scenario, the amount of fibers reaches 393.7 items/portion.

\section{Discussion}

According to our results, microfiber levels, ranging from 0.01 to 5.03 items $/ g$ w.w. were detected in mussels from Canada. Despite the similar analytical protocol applied, the study was focused on the occurrence of microfibers in field samples (Doucet et al., 2021). On the other hand, commercial mussels coming from Italian mariculture plants but treated with a different extraction protocol showed a prevalence of fibrous microplastics (Renzi et al., 2018). In this light, to improve comparability between studies, the main future challenge will be the development of standardized monitoring methods and protocols to harmonize laboratory procedures for microplastics analysis (Mercogliano et al., 2021).

Factors affecting microplastic levels also include mussel size, with significantly higher contamination in smaller mussels (Weber at al., 2021). The same trend was also observed for microfibers. Smaller mussels may contain more microfibers than larger mussels because in Mytilus species pumping and filtration rates decrease with higher soft tissues mass (w.w.) (Catarino et al., 2018; Doucet et al., 2021). The preliminary findings on microfiber contamination in commercial mussels from the Tyrrhenian Sea seem to confirm this relationship. Also, the obtained results regarding the microfiber color agree with those reported in the literature, probably due to the fact that blue, transparent, and black are the most common colors of microfibers in marine ecosystems (Gago et al., 2018). Bivalves are of particular interest because their extensive filter-feeding activity exposes them directly to microplastics present in the environment (Li et al., 2019), but in the case of commercial samples the entire supply chain which may affect the microplastic, including microfiber, levels should be considered (Dawson et al., 2021). Firstly, before the sale, commercial mussels may

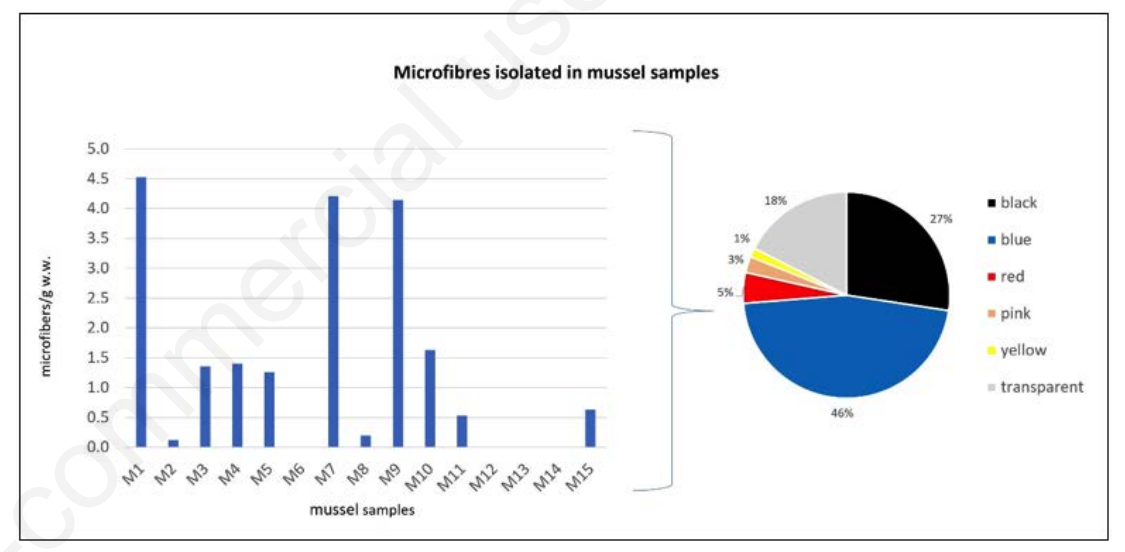

Figure 3. Number of microfibers/g w.w. and the relative percentage distribution of colors in mussels.

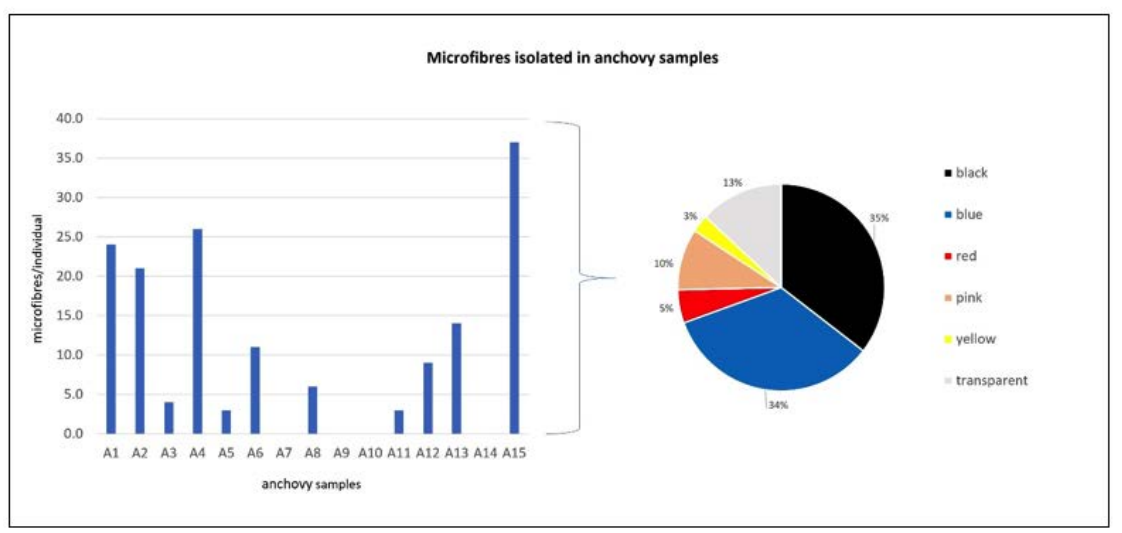

Figure 4. Number of microfibers per individual and the relative percentage distribution of colors in anchovies. 
undergo depuration which may favor the elimination of around $85 \%$ of the ingested microplastics, mostly for larger particles which are faster eliminated than smaller ones (Weber et al., 2021). However, small fibers $(50 \mu \mathrm{m}$ to $1 \mathrm{~mm})$, often accumulated by mussels, are little affected by the depuration due to the small size and their shape that increases the entanglement within the GI tract and the retention time (Kolandhasamy et al., 2018; Fernández and Albentosa, 2019). Lastly, samples from point-of-sale encompass additional sources of contamination including airborne fallout from clothing and machinery during processing or from packaging. Nevertheless, although these sources could impact the number of microplastics that contaminate the sample, only some of these can reach human consumers. For this to occur, bivalves, still alive, should ingest microplastics and transfer them to the gut cavity (Catarino et al., 2018; Dawson et al., 2021).

Microplastics impact a high proportion of the wild $E$. encrasicolus caught in the Mediterranean Sea and the occurrence of plastic particles was found also in other tissues than stomach contents (Collard et al., 2017). Different studies showed as fibers are the most represented microplastics in fish species (about $80 \%$ of the debris observed) (Rochman et al., 2015; Halstead et al., 2018). Microfibers were detected in $73 \%$ of commercial anchovies from the Tyrrhenian Sea, with a mean level of 9.06 microfibers/individual. Textile microfibers were also abundant in Adriatic food webs occurring in different fish species with average numbers (3-10 items/individual) and frequencies $(40-70 \%)$ higher than those reported for other plastic debris (Avio et al., 2020).

Capone et al. (2020) found a dominance of dark fibres also in anchovies from the Ligurian Sea. The authors hypothesized that black and blue fibres are not selected by anchovy, but probably filtered passively. On the other hand, the ingestion of transparent plastic debris may indicate active predation, especially for larger particles which may be mistaken for zooplankton. Once ingested fibres may clump and be hazardous if they block feeding or the passage of food (Lusher et al. 2013). Other negative effects may derive from the leaching of toxic substances from these particles, as monomers, dyes, plasticizers from the manufacture, and sorbed contaminants from the surrounding environment. Considering the occurrence of a high percentage of potential non-synthetic fibres (about $50 \%$ of the microfibres observed) in both the species, it should be noticed that also natural fibres are capable of releasing chemical compounds, especially associated dyes and additives (Halstead et al., 2019; Acharya et al., 2021).

The exposure to anthropogenic debris in marine biota is increasingly investigated with growing concerns regarding human health through trophic transfer. Mussels are important vectors for the transfer of microplastics into the human food chain ( $\mathrm{Li}$ et al., 2019). It was estimated that the consumption of $225 \mathrm{~g}$ of mussels may result in exposure to 900 plastic items (EFSA, 2016). In the current study, as the chemical characterization of microfibers was not performed, for a comprehensive evaluation of consumer exposure, both potential synthetic and natural fibres detected in the samples were considered. Using the same EFSA approach, the consumption of a portion of mussels from the Tyrrhenian Sea could determine the exposure to 299.25 potential plastic and natural microfibers, while in the worst-case scenario, the exposure may reach 1,012 microfibers/portion. Intakes can be reduced of about $14 \%$ in the case of cooked mussels if the cooking water is not consumed (Renzi et al., 2018). Moreover, microplastics may undergo additional fragmentation and degradation when subjected to temperatures near water boiling (Renzi et al., 2019).

High plastic debris concentrations have been found also in fish guts, which are usually removed before human consumption. In the case of small pelagic fish which may be consumed as a whole, the digestive tract is eaten, leading to some exposure (EFSA, 2016; Compa et al., 2018; Renzi et al., 2019). A portion of $150 \mathrm{~g}$ of anchovies not gutted from the Tyrrhenian Sea may contain 135.6 potential plastic and natural microfibers, and in the worst-case scenario, the amount of fibres reaches 393.7 items/portion. However, removing the digestive tract does not totally eliminate the risk of microplastic intake by consumers since the occurrence of these particles was also assessed in the eviscerated flesh of dried fish (Karami et al., 2017). At the moment, despite the evaluation of human exposure through commonly consumed foods showed that fibers are the most commonly ingested type of microplastic by humans, the extent of microfiber contamination in seafood remains less recognized (Cox et al., 2019; Doucet et al., 2021). The study of microfibers levels in commercial samples may also reflect the contribution from the processing and point-of-sale environment, and their quantification should be included as food safety management measures (Li et al., 2019; Dawson et al., 2021).

\section{Conclusions}

Microplastic pollution is ubiquitous in the global environment. The bioavailability of microplastics depends on their size, density, abundance, and shape. More recently, natural, and synthetic textile fibers have become a matter of concern. However, despite microfibers are among the most observed forms of plastic debris in the marine environment, they are largely underrepresented in ecotoxicological studies. Preliminary findings revealed the occurrence of potential plastic and natural microfibers in over $70 \%$ of mussels and anchovies from the Tyrrhenian Sea sold for human consumption. Microfiber content was negatively correlated with mussel size, but further studies, involving a higher number of samples, are needed to better understand the factors that influence mussel uptake. Anchovies may both passively filtered microfibers and mistaking them with prey. Moreover, as point-of-sale samples, they encompass additional sources of contamination. The consumption of a portion of mussels and anchovies may lead to human exposure to potential synthetic and natural microfibers. However, more research is required to adequately assess the risk that microplastics, including microfibers, may pose in marine organisms and the implications for food safety and human health.

\section{References}

Acharya S, Rumi SS, Hu Y, Abidi N, 2021. Microfibers from synthetic textiles as a major source of microplastics in the environment: A review. Text Res J 1-21.

Avio CG, Pittura L, d'Errico G, Abel S, Amorello S, Marino G, Regoli F, 2020. Distribution and characterization of microplastic particles and textile microfibers in Adriatic food webs: general insights for biomonitoring strategies. Environ Pollut 258:1-13.

Capone A, Petrillo M, Misic C, 2020. Ingestion and elimination of anthropogenic fibres and microplastic fragments by the European anchovy (Engraulis encrasicolus) of the NW Mediterranean Sea. Mar Biol 167:1-15.

Catarino AI, Macchia V, Sanderson WG, Thompson RC, Henry TB, 2018. Low levels of microplastics (MP) in wild mussels indicate that MP ingestion by humans is minimal compared to exposure via household fibres fallout during a meal. Environ Pollut 237:675-684.

Collard F, Gilbert B, Compère P, Eppe G, Das K, Jauniaux T, Parmentier E, 2017. 
Microplastics in livers of European anchovies (Engraulis encrasicolus, L.). Environ Pollut 229:1000-1005.

Compa M, Ventero A, Iglesias M, Deudero S, 2018. Ingestion of microplastics and natural fibres in Sardina pilchardus (Walbaum, 1792) and Engraulis encrasicolus (Linnaeus, 1758) along the Spanish Mediterranean coast. Mar Pollut Bull 128:89-96.

Cox KD, Covernton GA, Davies HL, Dower JF, Juanes F, Dudas SE, 2019. Human consumption of microplastics. Envir Sci Tech 53:7068-74.

Crea, 2017. Centro di Ricerca Alimenti e Nutrizione. Linee guida per una sana alimentazione. Dossier Scientifico, Edizione 2017, Capitolo 10.

Dawson AL, Santana MF, Miller M.E, Kroon FJ, 2021. Relevance and reliability of evidence for microplastic contamination in seafood: a critical review using Australian consumption patterns as a case study. Environ Pollut 276:116684.

Doucet CV, Labaj AL, Kurek J, 2021. Microfiber Content in Freshwater Mussels from Rural Tributaries of the Saint John River, Canada. Water Air Soil Poll 232:1-12.

EFSA Panel on Contaminants in the Food Chain (CONTAM), 2016. Presence of microplastics and nanoplastics in food, with particular focus on seafood. Efsa J 14:04501.

FAO, 2011. Review of the state of world marine Fishery resources. FAO Fisheries and Aquaculture Technical Paper No. 569. Rome, FAO: 334 pp.

Fernández B, Albentosa M, 2019. Insights into the uptake, elimination and accumulation of microplastics in mussel. Environ Pollut 249:321-9.

Fossi MC, Pedà C, Compa M, Tsangaris C, Alomar C, Claro F, Baini M, 2018. Bioindicators for monitoring marine litter ingestion and its impacts on Mediterranean biodiversity. Environ Pollut 237:1023-40.
Gago J, Carretero O, Filgueiras AV, Viñas, L, 2018. Synthetic microfibers in the marine environment: A review on their occurrence in seawater and sediments. Mar Pollut Bull 127:365-76.

GESAMP, 2015. Sources, fate and effects of microplastics in the marine environment: a global assessment. Rep. Stud. GESAMP No. 90

Halstead JE, Smith JA, Carter EA, Lay PA, Johnston EL, 2018. Assessment tools for microplastics and natural fibres ingested by fish in an urbanised estuary. Environ Pollut 234:552-61.

Karami A, Golieskardi A, Ho YB, Larat V, Salamatinia B, 2017. Microplastics in eviscerated flesh and excised organs of dried fish. Sci Rep 7:1-9.

Kolandhasamy P, Su L, Li J, Qu X, Jabeen K, Shi H, 2018. Adherence of microplastics to soft tissue of mussels: a novel way to uptake microplastics beyond ingestion. Sci Total Environ 610:635-40.

Li Q, Sun C, Wang Y, Cai H, Li L, Li J, Shi, $\mathrm{H}, 2019$. Fusion of microplastics into the mussel byssus. Environ Pollut 252:420-6.

Lusher AL, Mchugh M, Thompson RC, 2013. Occurrence of microplastics in the gastrointestinal tract of pelagic and demersal fish from the English Channel. Mar Pollut Bull 67:94-9.

Mercogliano R, Santonicola S, Raimo G, Gasperi M, Colavita G, 2021. Extraction and identification of microplastics from mussels: Method development and preliminary results. Ital J Food Saf 10(1).

Patti B, Zarrad R, Jarboui O, Cuttitta A, Basilone G, Aronica S, Mazzola S, 2018. Anchovy (Engraulis encrasicolus) early life stages in the Central Mediterranean Sea: connectivity issues emerging among adjacent sub-areas across the Strait of Sicily. Hydrobiologia 821:25-40.

Renzi M, Guerranti C, Blašković A, 2018. Microplastic contents from maricul- tured and natural mussels. Mar Pollut Bull 131:248-51.

Renzi M, Specchiulli A, Blašković A, Manzo C, Mancinelli G, Cilenti L, 2019. Marine litter in stomach content of small pelagic fishes from the Adriatic Sea: sardines (Sardina pilchardus) and anchovies (Engraulis encrasicolus). Environ Sci Pollut R 26:2771-81.

Rios-Fuster B, Alomar C, Compa M, Guijarro B, Deudero S, 2019. Anthropogenic particles ingestion in fish species from two areas of the western Mediterranean Sea. Mar Pollut Bull 144:325-33.

Rochman CM, Tahir A, Williams SL, Baxa DV, Lam R, Miller JT, Teh SJ, 2015. Anthropogenic debris in seafood: Plastic debris and fibers from textiles in fish and bivalves sold for human consumption. Sci Rep 5:1-10.

Savoca S, Capillo G, Mancuso M, Faggio C, Panarello G, Crupi R, Spanò N, 2019. Detection of artificial cellulose microfibers in Boops boops from the northern coasts of Sicily (Central Mediterranean). Sci Total Environ 691:455-65.

Smith M, Love DC, Rochman CM, Neff RA, 2018. Microplastics in seafood and the implications for human health. Curr Environ Health Rep 5:375-86.

Ward JE, Zhao S, Holohan BA, Mladinich KM, Griffin TW, Wozniak J, Shumway SE, 2019. Selective ingestion and egestion of plastic particles by the blue mussel (Mytilus edulis) and eastern oyster (Crassostrea virginica): implications for using bivalves as bioindicators of microplastic pollution. Envir Sci Tech 53:8776-84.

Weber A, Jeckel N, Weil C, Umbach S, Brennholt N, Reifferscheid G, Wagner M, 2021. Ingestion and Toxicity of Polystyrene Microplastics in Freshwater Bivalves. Environ Toxicol Chem 1-14. 